\title{
Variation of total serum sialic acid concentration in postmenopausal women
}

\author{
OCTAVIAN GABRIEL OLARU ${ }^{1}$, GIANINA IOANA CONSTANTIN ${ }^{2}$ and CATALINA MONICA PENA ${ }^{2}$ \\ ${ }^{1}$ Department of Obstetrics and Gynecology, 'Carol Davila' University of Medicine and Pharmacy, \\ 040292 Bucharest; ${ }^{2}$ Department of Biology of Aging Research, 'Ana Aslan’ National Institute \\ of Gerontology and Geriatrics, 011241 Bucharest, Romania
}

Received May 1, 2020; Accepted June 1, 2020

DOI: $10.3892 /$ etm.2020.8873

\begin{abstract}
Given its location and ubiquitous distribution, sialic acid can mediate or modulate a wide variety of physiological and pathological processes; however, there is scarce data regarding the associations between sialic acid serum levels and sex, age and menopause. The present study evaluated the age-related changes in serum sialic acid (SA) levels in 97 elderly subjects, including men and postmenopausal women. A significant increase in serum levels of sialic acid in postmenopausal women and a significant decrease in men were observed in an age-dependent manner. Furthermore, in postmenopausal women, positive correlations were observed between the total serum sialic acid level and age in all decades and subgroups. The total serum concentration of sialic acid in the postmenopausal women group exhibited a particular pattern; significantly lower levels were observed in subjects in the intermediate postmenopausal period compared with those in the first decade of post menopause and then higher levels again as the women get older (late climax), thus the concentration increased according to the age of the individual.
\end{abstract}

\section{Introduction}

The term 'sialic acid' (SA) originates from the Greek word 'sialon', which means saliva, and it was introduced for the first time in 1952 by Gunnar Blix, a Swedish biochemist who found this new acidic compound in saliva, 15 years earlier, in 1937 (1).

The main chemical compound of SA is N-acetylneuraminic acid (NANA), a monocarboxylic acid with the formula

Correspondence to: Dr Octavian Gabriel Olaru, Department of Obstetrics and Gynecology, 'Carol Davila' University of Medicine and Pharmacy, 10 Bucur Street, Sector 4, 040292 Bucharest, Romania E-mail: octavian_olaru@umfcd.ro

Abbreviations: SA, sialic acid; NANA, N-acetylneuraminic acid

Key words: sialic acid, $\mathrm{N}$-acetylneuraminic acid, menopause, aging, elderly women
$\mathrm{C}_{11} \mathrm{H}_{19} \mathrm{O}_{9} \mathrm{~N}$ (1). It has been found that there is a whole family of related compounds that originate from NANA and SA became the generic name for this family of $>50$ members of acid neuraminic derivatives (sugar chains or glycans) (1). Other members of the SA family can be obtained from the molecule of neuraminic acid by changing the amino group with a hydroxyl substituent, or methyl, lactyl, acetyl or phosphate group.

Chemically, members of this family are considered condensation products of $\mathrm{N}$-acetylhexosamine with pyruvic acid. Gunnar Blix agreed that this unacetylated primary compound should be called neuraminic acid, and the term SA should be used as a collective term for acetylated and glycosylated derivatives of neuraminic acid (1).

SA serves an important role in the interaction, communication and signaling between cells, cell aggregation, immune response, reproduction, tissue development and regeneration, and also in human diseases, including in the infection process, tumor growth and metastasis (2). At the surface of animal cells and microorganisms there is a dense and complex array of glycans, mostly attached to proteins and lipids, which mediate specific roles in health and disease $(3,4)$.

Given their location and ubiquitous distribution, SAs can mediate or modulate a wide variety of physiological and pathological processes, however, further understanding of SAs is required and many hypotheses are awaiting clarification $(5,6)$. The aim of the present study was to evaluate the age-related changes of serum SA in elderly individuals, including men and postmenopausal women.

\section{Patients and methods}

The present study was a cross-sectional single center study comprising 97 subjects, including 77 women and 20 men, aged $\geq 55$ years. All subjects were admitted to 'Ana Aslan' National Institute of Gerontology and Geriatrics (Bucharest, Romania), and selected for the study between 2014 and 2019. The Ethics Committee of the 'Ana Aslan' National Institute of Gerontology and Geriatrics approved the study protocol. Each subject signed an informed consent form prior to the study. All procedures performed in the study were in accordance with the ethical standards of the National Research Committee, and the Helsinki Declaration and its later amendments. 
Eligible patients included men and postmenopausal women, who were able to give informed consent, and who were able to communicate and cooperate, for example they did not have Alzheimer's disease at an advanced stage, a cognitive disease nor advanced disabilities. The exclusion criteria were: i) age $<55$ years; ii) women that did not have a postmenopausal status; and iii) subjects with a severe or disabling pathology, including dementia, severe physical disabilities, neoplasia, severe or acute inflammatory syndrome, stroke, cardiac failure, kidney failure and cirrhosis. The age range of the women was 55-87 years, with a mean age of 67.74 \pm 8.64 years, and the age range of the men was 55-87 years, with a mean age of $69.05 \pm 10.43$ years.

The selected subjects were first divided into two groups: i) group 1 , men $(n=20)$; and ii) group 2, women $(n=77)$. The group of women was further divided into three subgroups depending on age: i) subgroup $1(n=32)$; age range, 55-64 years; mean age, $59.43 \pm 3.30$ years; ii) subgroup $2(n=28)$; age range, $65-74$ years; mean age, $69.71 \pm 2.73$ years; and iii) subgroup 3 $(n=17)$; age range, $75-87$ years; mean age $80.11 \pm 3.67$ years.

Venous blood samples were obtained following overnight fasting, and serum was collected after $20 \mathrm{~min}$ of centrifugation at $1,000 \mathrm{x} \mathrm{g}$ and refrigerated at $-70^{\circ} \mathrm{C}$ until use.

Total SA in serum samples was determined by the standard Ehrlich's method, a colorimetric assay, using standard reagents and chemicals with an analytical grade, which were purchased from Sigma-Aldrich; Merck KGaA. According to this method, the supernatant of serum containing SA chemically reacted with the Ehrlich's reagent and produced a colorimetric reaction that was quantitatively measured using a spectrophotometer (2). This procedure is based on the release of bound SA by heating with $5 \%$ perchloric acid. After cooling in the ice bath at $0^{\circ} \mathrm{C}$ and brief centrifugation for $5 \mathrm{~min}$ at $1,000 \mathrm{x} \mathrm{g}$ and $22^{\circ} \mathrm{C}$, the supernatant was heated for $15 \mathrm{~min}$ with Ehrlich's reagent at $100^{\circ} \mathrm{C}$. Subsequently, the absorbance of the color developed in the sample was measured at $565 \mathrm{~nm}$, and the serum concentration of SA was expressed in $\mathrm{mg} / \mathrm{dl}$.

Statistical analysis. All data are presented as mean \pm standard deviation (SD). Statistical analysis was performed by Student's t-test using Excel 7.0 (Microsoft Corporation) and SPSS 8.0 (SPPS, Inc.) software. Pearson's correlation coefficients (r) were calculated to evaluate the correlations between serum $\mathrm{SA}$ and age. $\mathrm{P}<0.05$ was considered to indicate a statistically significant difference.

\section{Results and Discussion}

SAs are a class of sugars that belong to the larger family of glycans. Current science includes a special field 'glycobiology', which refers to the physiological and pathological interactions and processes of SAs. This class of glycans has four main categories of functions (5): i) Structural and modulator roles through their negative charge and hydrophilicity; ii) components of binding sites for diverse pathogens and toxins; iii) a role in binding proteins; and iv) molecular mimicry; microbial pathogens decorated with SAs assist in invasion of host immunity.

SA is very important in blood circulation, having a major function in non-adherence of blood cells to the endovascular
Table I. Clinical and serum biochemical parameters of subjects included in the study groups.

\begin{tabular}{lcc}
\hline Parameter & Women $(\mathrm{n}=77)$ & Men $(\mathrm{n}=20)$ \\
\hline Age, years & $67.74 \pm 8.64$ & $69.05 \pm 10.43$ \\
Body mass index, $\mathrm{kg} / \mathrm{m}^{2}$ & $29.07 \pm 5.66$ & $28.78 \pm 4.00$ \\
Glucose, mg/dl & $127.51 \pm 49.26$ & $132.45 \pm 45.98$ \\
Total cholesterol, mg/dl & $229.41 \pm 44.53$ & $216.8 \pm 44.67$ \\
HDL-cholesterol, mg/dl & $48.82 \pm 15.08$ & $44.53 \pm 16.38$ \\
LDL-cholesterol, mg/dl & $140.89 \pm 38.14$ & $133.13 \pm 41.08$ \\
Triglycerides, mg/dl & $155.55 \pm 85.28$ & $158.4 \pm 83.99$ \\
Serum SA, mg/dl & $88.07 \pm 19.74$ & $89.15 \pm 14.8$ \\
\hline
\end{tabular}

Data are presented as the mean \pm standard deviation. SA, sialic acid.

epithelium (7). Total serum SA has been reported in some studies as a cardiovascular risk factor, and it is increased following menopause in females, however, the reason is not clear (8).

A study published in 1998 by Crook et al (9) stated that in females there is a strong univariate correlation between total serum SA level and plasma fasting insulin and glucose concentration, whereas in males there is a weaker univariate correlation between total serum SA and fasting plasma glucose and the insulin resistance index. In addition, total serum SA is significantly correlated with fasting serum cholesterol concentrations and body mass index in females, but not in males.

Other studies have shown that SA represents a cardiovascular risk factor, as it is associated with increased cardiovascular mortality (10) and cerebrovascular disease $(8,11)$. In addition, it has been demonstrated that SA levels are elevated in patients with type I and II diabetes mellitus, therefore it is assumed that SA could be associated with insulin resistance or hyperinsulinemia $(12,13)$.

Furthermore, SA could play a role in tissue repair, for example in regeneration of axons and remodeling of synapses (14). The roles of SA in infections are complex; on the one hand they provide protection, but on the other hand, SA serves a role as a Trojan Horse when a germ mimics the host structures $(15,16)$. SA also plays a key role in the fertility maturation and activation of sperm cells (17-19), as well as development of the embryo $(20,21)$. Some studies have found a link between serum estrogen levels and SA on the surface of endometrial cells or changes that determine the pathological state in endometrial cancer or endometriosis $(22,23)$.

Crook et al (9) had already studied the changes of serum SA levels in adult age-matched women (pre-menopausal, perimenopausal and post-menopausal women), and their conclusion of the study was that there is no significant difference between the serum SA concentration in young women compared with pre-, peri- or post-menopausal women (24). However, in an age-related study Mehdi et al (25) in 2012 found that in elderly women and men, the mean values of serum SA were elevated.

Therefore, there are no clear conclusions regarding the correlations between serum concentrations of SA, age and menopause. 
Table II. Clinical and serum biochemical parameters of women included in the study divided by age.

\begin{tabular}{lccc}
\hline & $\begin{array}{c}\text { Subgroup I } \\
\text { Parameter }\end{array}$ & $\begin{array}{c}\text { Subgroup II } \\
(65-64 \text { years; } \mathrm{n}=32)\end{array}$ & $\begin{array}{c}\text { Subgroup III } \\
(75-87 \text { years; } \mathrm{n}=28)\end{array}$ \\
\hline Age, years & $59.43 \pm 3.30$ & $69.71 \pm 2.73$ & $80.11 \pm 3.67$ \\
Body mass index, $\mathrm{kg} / \mathrm{m}^{2}$ & $28.27 \pm 5.17$ & $30.48 \pm 6.48$ & $28.25 \pm 4.90$ \\
Glucose, $\mathrm{mg} / \mathrm{dl}$ & $121.65 \pm 40.06$ & $121.60 \pm 31.54$ & $148.29 \pm 78.42$ \\
Total cholesterol, mg/dl & $226.78 \pm 50.59$ & $230.57 \pm 34.61$ & $232.47 \pm 49.13$ \\
HDL-cholesterol, mg/dl & $49.25 \pm 15.74$ & $54.55 \pm 14.68$ & $38.56 \pm 8.14$ \\
LDL-cholesterol, mg/dl & $140.55 \pm 43.27$ & $135.88 \pm 27.65$ & $149.78 \pm 43.17$ \\
Triglycerides, $\mathrm{mg} / \mathrm{dl}$ & $151.71 \pm 91.38$ & $144.82 \pm 65.52$ & $180.47 \pm 101.15$ \\
Serum SA, $\mathrm{mg} / \mathrm{dl}$ & $87.91 \pm 18.23$ & $82.42 \pm 12.66$ & $97.69 \pm 27.98$ \\
\hline
\end{tabular}

Data are presented as the mean \pm standard deviation. SA, sialic acid.
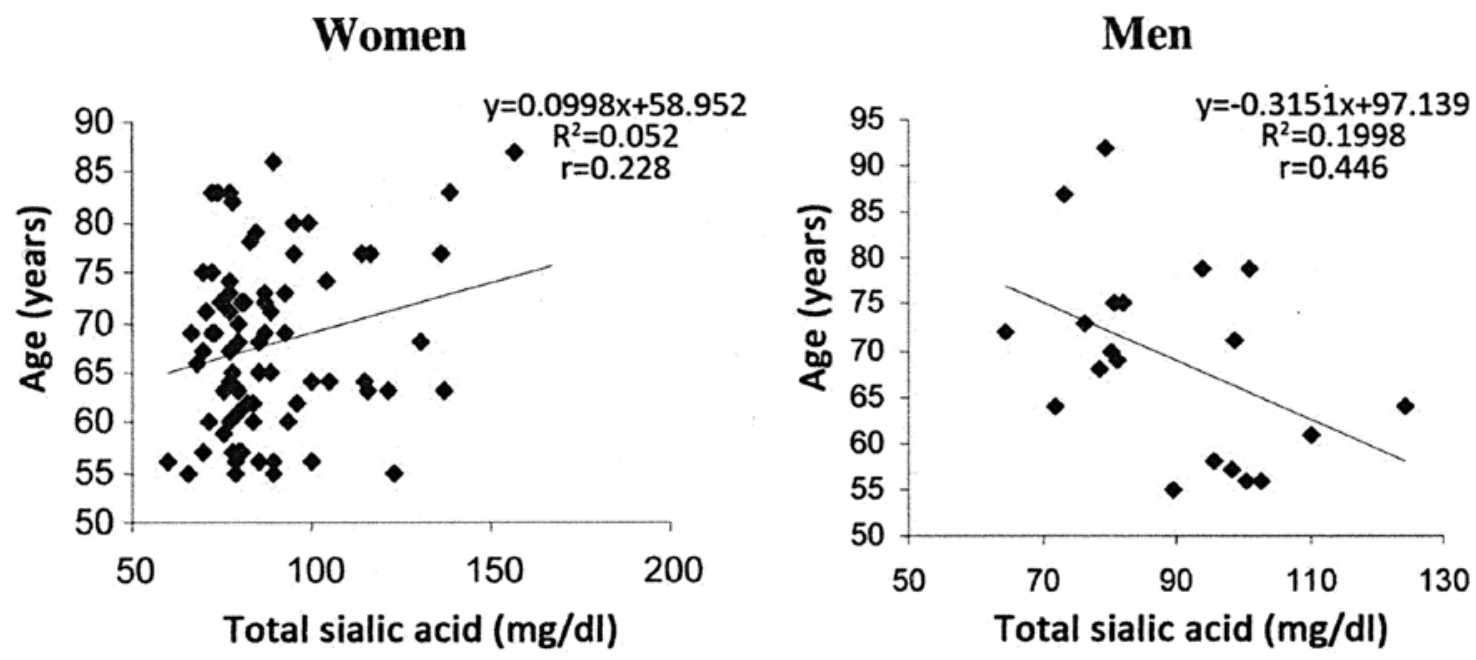

Figure 1. Pearson's correlation between individual serum SA levels and chronological age of postmenopausal women ( $\mathrm{n}=77)$ and men $(\mathrm{n}=20)$. SA, sialic acid.

By performing statistical analysis of the data presented in Table I, it was demonstrated there were no significant differences between men and women for the determined clinical and biochemical parameters, except for a slight increase in the mean value of glucose in men compared with women (Table I).

Differences were identified when analyzing the correlations between the levels of SA and the individuals' chronological age in the group of postmenopausal women compared with the group of men. A significant positive correlation $(\mathrm{P}=0.0461)$ was identified between individual values of total SA and age in the group of postmenopausal women, and a significant negative correlation $(\mathrm{P}=0.0482)$ was observed in the group of men (Fig. 1).

The group of postmenopausal women was further studied by dividing subjects by age into the following subgroups: i) 55-64 years; ii) 65-74 years; and iii) 75-87 years. Statistical analysis of the data presented in Table II allowed us to compare the variation of the biochemical and clinical parameters according to age, for these three subgroups of women.

The mean values for glucose and total cholesterol increased with age; the total cholesterol levels increased slowly and steadily for each decade of age, while the glucose levels were similar in the first two subgroups and increased after the age of 75 years. The mean values of HDL and BMI also increased between the first two age subgroups, and in the third subgroup they markedly decreased, in such a way that the mean values in the third group were lower than those measured for individuals in the first age group. For LDL and TG, the changes in the mean values according to age were contradictory to those for HDL and BMI (Table II).

By analyzing the group of postmenopausal women to see how the mean values of serum SA varied with age, a significant decrease $(\mathrm{P}<0.01)$ between the first and second subgroups was observed, followed by a significant increase $(\mathrm{P}<0.001)$ between the second and third age groups. In addition, in postmenopausal women, positive correlations were observed between the total serum SA and age in all the decade subgroups; however, they were only statistically significant in subgroup I ( $\mathrm{P}=0.0283)$ (subgroup II, $\mathrm{P}=0.667$; subgroup III, $\mathrm{P}=0.346$ (Fig. 2).

In conclusion, regarding the age-related changes in serum concentrations of SA, the present study found differences depending on sex; namely a significant increase in postmenopausal women compared with a significant decrease in men. 

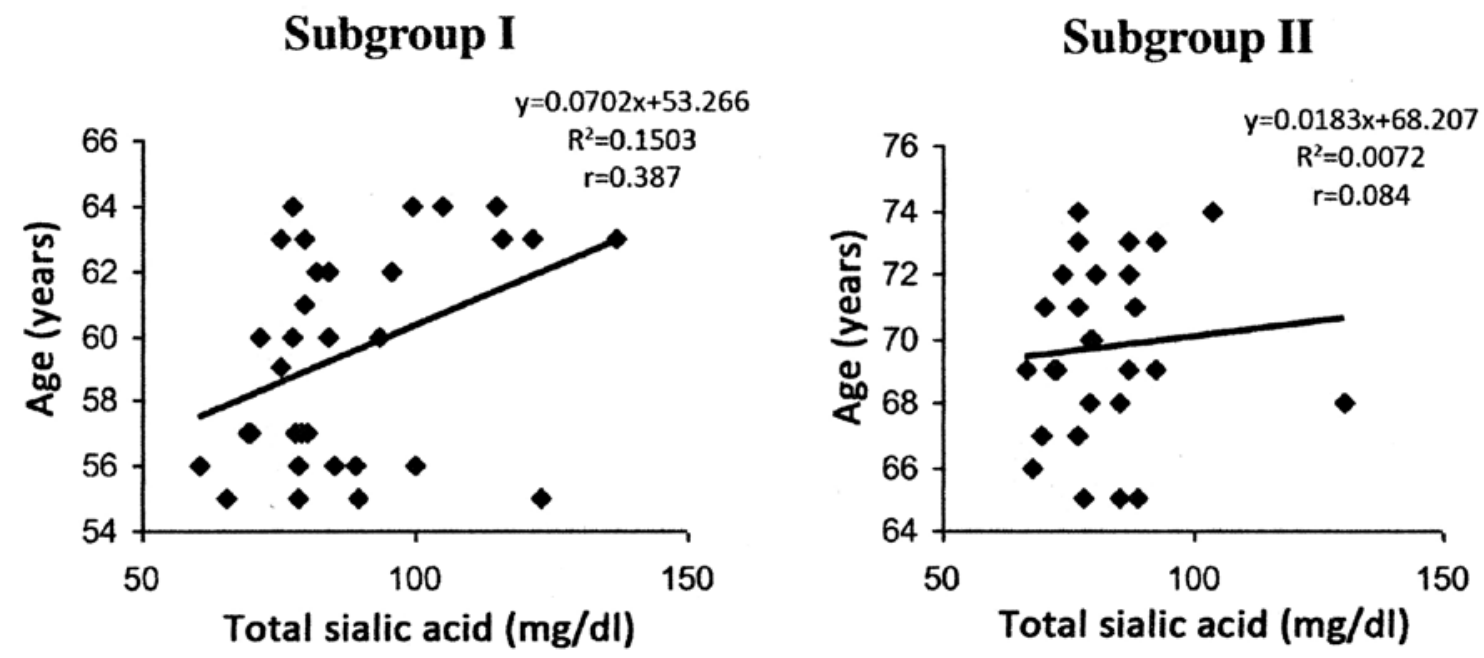

Subgroup III

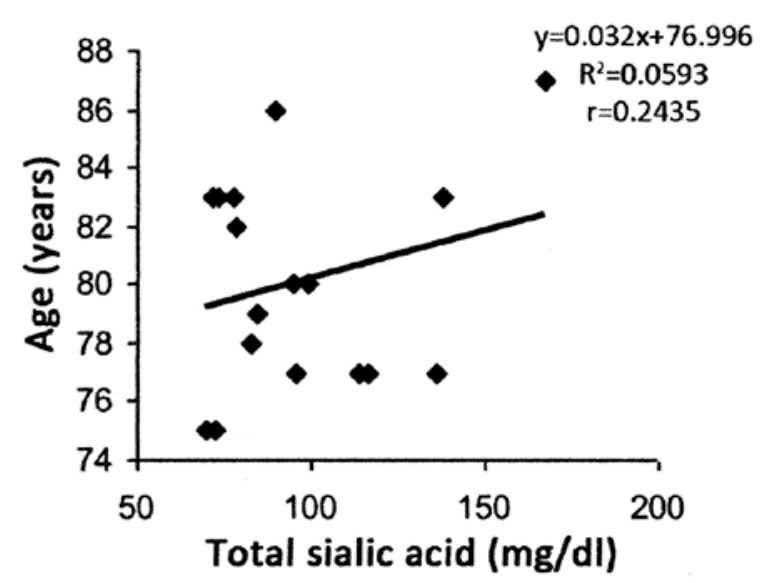

Figure 2. Pearson's correlation between individual serum SA levels and chronological age in the three decade subgroups of postmenopausal women. SA, sialic acid.

Although overall an age-related increase in SA serum levels was observed in postmenopausal women, for them this does not evolve uniformly, a slowdown in growth was identified in the decade following the postmenopausal period, followed by a significant increase with age.

The sex-related significant differences identified in the present study could be associated with the differences in sex-morbidity in the postmenopausal period, after which uniformity occur as the physiological differences tend to decrease at older ages.

\section{Acknowledgements}

Not applicable.

\section{Funding}

No funding was received.

\section{Availability of data and materials}

All data generated or analyzed during this study are included in this published article.

\section{Authors' contributions}

OGO contributed to the establishment of the study groups, the acquisition, analysis and interpretation of the patient data, and the writing of the manuscript. GIC contributed to the establishment of the study groups, the analysis and interpretation of the patient data, and the writing of the manuscript. CMP contributed to the establishment of the study groups, and the analysis and interpretation of the patient data. All authors read and approved the final manuscript.

\section{Ethics approval and consent to participate}

The Ethics Committee of 'Ana Aslan' National Institute of Gerontology and Geriatrics (Bucharest, Romania) approved the study protocol. Each subject signed an informed consent form prior to the study. All procedures were performed in accordance with the ethical standards of the National Research Committee, and the Helsinki Declaration and its later amendments.

\section{Patient consent for publication}

Not applicable. 


\section{Competing interests}

The authors declare that they have no competing interests.

\section{References}

1. Varki A and Schauer R: Sialic acids.In: Essentials of Glycobiology. 2nd edition. Varki A, Cummings RD, Esko JD, Freeze HH, Stanley P, Bertozzi CR, Hart GW and Etzler ME (eds). Cold Spring Harbor Laboratory Press, Cold Spring Harbor, NY, 2009

2. Ghosh S: Sialic acid and biology of life: an introduction. In: Sialic Acids and Sialoglycoconjugates in the Biology of Life, Health and Disease. Ghosh S (ed). Academic Press, pp1-61, 2020.

3. Pena CM and Constantin IG: Sialic acid modifications in aging and pathology. Rom J Gerontol Geriatr 6: 21-26, 2017.

4. Sillanaukee P, Pönniö M and Jääskeläinen IP: Occurrence of sialic acids in healthy humans and different disorders. Eur J Clin Invest 29: 413-425, 1999.

5. Varki A: Sialic acids in human health and disease. Trends Mol Med 14: 351-360, 2008.

6. Papacocea T, Buraga I, Papacocea R, Badarau AI, Buraga M, Ciornei C, Mihai G, Stoian I and Adam D: Antioxidant enzymespotential targets in intracerebral haemorrhage. Farmacia 62 $1118-1125,2014$

7. Born GV and Palinski W: Unusually high concentrations of sialic acids on the surface of vascular endothelia. Br J Exp Pathol 66 543-549, 1985.

8. Lindberg G, Råstam L, Gullberg B and Eklund GA: Serum sialic acid concentration predicts both coronary heart disease and stroke mortality: Multivariate analysis including 54,385 men and women during 20.5 years follow-up. Int J Epidemiol 21: 253-257, 1992.

9. Crook M, Lumb P, Andrews V and Swaminathan R: Serum total sialic acid, a reputed cardiovascular risk factor, and its relationship to lipids, plasma fasting insulin, blood pressure and body mass index in normal individuals. Clin Sci (Lond) 95: 53-57, 1998.

10. Lindberg G, Eklund GA, Gullberg B and Råstam L: Serum sialic acid concentration and cardiovascular mortality. BMJ 302: 143-146, 1991

11. Papacocea MT, Badarau AI, Radoi M and Papacocea RI: Predictive role of biochemical plasma factors in patients with severe traumatic brain injuries. Rev Chim 70: 1754-1757, 2019.

12. Rajappa M, Ikkruthi S, Nandeesha H, Satheesh S, Sundar I, Ananthanarayanan PH and Harichandrakumar KT: Relationship of raised serum total and protein bound sialic acid levels with hyperinsulinemia and indices of insulin sensitivity and insulin resistance in non-diabetic normotensive obese subjects. Diabetes Metab Syndr 7: 17-19, 2013.
13. Khalili P, Sundström J, Jendle J, Lundin F, Jungner I and Nilsson PM: Sialic acid and incidence of hospitalization for diabetes and its complications during 40-years of follow-up in a large cohort: The Värmland survey. Prim Care Diabetes 8: 352-357, 2014.

14. El Maarouf A, Petridis AK and Rutishauser U: Use of polysialic acid in repair of the central nervous system. Proc Natl Acad Sci USA 103: 16989-16994, 2006.

15. Schauer R: Achievements and challenges of sialic acid research. Glycoconj J 17: 485-499, 2000.

16. Vimr ER, Kalivoda KA, Deszo EL and Steenbergen SM: Diversity of microbial sialic acid metabolism. Microbiol Mol Biol Rev 68: 132-153, 2004.

17. Mengerink KJ and Vacquier VD: Glycobiology of sperm-egg interactions in deuterostomes. Glycobiology 11: R37-R43, 2001.

18. Ma X, Pan Q, Feng Y, Choudhury BP, Ma Q, Gagneux P and Ma F: Sialylation facilitates the maturation of mammalian sperm and affects its survival in female uterus. Biol Reprod 94: 123, 2016.

19. Chatterji U, Sen AK, Schauer R and Chowdhury M: Paracrine effects of a uterine agglutinin are mediated via the sialic acids present in the rat uterine endometrium. Mol Cell Biochem 215: $47-55,2000$.

20. Schwarzkopf M, Knobeloch KP, Rohde E, Hinderlich S, Wiechens N, Lucka L, Horak I, Reutter W and Horstkorte R: Sialylation is essential for early development in mice. Proc Natl Acad Sci USA 99: 5267-5270, 2002.

21. Ioffe E and Stanley P: Mice lacking N-acetylglucosaminyl transferase I activity die at mid-gestation, revealing an essential role for complex or hybrid N-linked carbohydrates. Proc Natl Acad Sci USA 91: 728-732, 1994

22. Choi H, Chung T, Choi H, Han JH, Choi JH, Kim CH and Ha KT: Increased $\alpha 2-6$ sialylation of endometrial cells contributes to the development of endometriosis. Exp Mol Med 50: 1-12, 2018.

23. Paszkowska A, Cybulski M, Semczuk A, Postawski K and Berbe $\mathrm{H}$ : Total sialic acid content in endometrial cancer tissue in relation to normal and hyperplastic human endometrium. Cancer Detect Prev 24: 459-463, 2000.

24. Crook M, Collins D, Lumb P, Fogelman I and Treloar A: The relationship between the female menopause and serum sialic acid, a known cardiovascular risk factor. Eur J Obstet Gynecol Reprod Biol 76: 185-187, 1998.

25. Mehdi MM, Singh P and Rizvi SI: Erythrocyte sialic acid content during aging in humans: Correlation with markers of oxidative stress. Dis Markers 32: 179-186, 2012. 